\title{
Prison officers' attitudes towards self-harm in prisoners
}

\author{
Marta Sousa $^{\mathrm{a}, *}$, Rui Abrunhosa Gonçalves ${ }^{\mathrm{a}}$, Ana Rita Cruz ${ }^{\mathrm{a}, 1}$, Andreia de Castro Rodrigues ${ }^{\mathrm{a}, \mathrm{b}}$ \\ ${ }^{\text {a }}$ CIPsi (Center of Research in Psychology), School of Psychology, University of Minho, Campus de Gualtar, 4710-057 Braga, Portugal \\ ${ }^{\mathrm{b}}$ Faculty of Law, University Lusíada North (Porto), Rua Dr. Lopo de Carvalho, 4369-006 Porto, Portugal
}

A R T I C L E I N F O

\section{Keywords:}

Self-harm

Self-injury

Prison officers' attitudes

Suicide

Prisoners

\begin{abstract}
A B S T R A C T
Prison officers are the agents that have the most contact with prisoners during imprisonment and are essential for control prisoners at risk. Because of that, it is essential to understand their attitudes towards prisoners who self-harm because their attitudes predispose the behavior in situations of self-harm. Thus, our study aimed to explore the attitudes of prison officers regarding prisoners who self-harm. The results revealed that prison officers did not advocate harsh treatment for self-harming prisoners. However, they tend to reveal some difficulties in understanding the causes of self-harm, reproducing the negative myths referred to in the literature. They also tend to neglect the fact that these behaviors may, in some cases, culminate in suicide. These results highlight the need for specific training about this phenomenon, not only in prison officers initial training but also in continuing training, identifying issues of particular importance to address, such as interpersonal skills and behavioral strategies to deal with incarcerated individuals who self-harm. We also advocate for the importance of reinforcing prison officers' role as first-line responders, empowering these agents in their social responsibility towards prisoners well being and the way penal justice is implemented.
\end{abstract}

\section{Introduction}

Self-harm is a significant social problem. The high prevalence of this behavior and its predictive power in a possible suicidal behavior makes this phenomenon a concern (Cooper et al., 2005; Hawton, Linsell, Adeniji, Sariaslan, \& Fazel, 2014; Lohner \& Konrad, 2006; Wilkinson, Kelvin, Roberts, Dubicka, \& Goodyer, 2011; Zahl \& Hawton, 2004). Although self-harm is more prevalent among prisoners than in the general population, this is still a poorly studied phenomenon. Researchers estimated that the annual prevalence of self-harm in prison is $5-6 \%$ in men and $20-24 \%$ in women (Hawton et al., 2014). Also, other authors have demonstrated that the prevalence of self-harm behaviors without suicidal intent in male prisons is $34.8 \%$ (Sakelliadis, Papadodima, Sergentanis, Giotakos, \& Spiliopoulou, 2010). Despite variations, which are consistent with the possible underreported information in prisons (e.g., Daggett \& Camp, 2009), these values are much higher than the $0.6 \%$ found in general population (Hawton et al., 2014). In Portugal, access to official data of the number of self-harm behaviors occurring in prisons is not publicly available. Hence, prevalence, type, severity, and continuity of such acts are not known.

\subsection{Defining self-harm in prison}

In the literature, there is a lack of consensus in the concepts used to define behaviors against the individual. Specifically, different concepts are associated with self-harm behaviors. "Self-harm" may classify only suicidal acts (e.g., Carli et al., 2011), or may be used in a broader perspective including other motivations, besides lethal ones, such as emotional relief and anger externalization. In our study, we defined self-harm as any injury act an individual cause to himself regardless of the motive or lethal intent (Livingston, 1997 cited in Ireland, 2000; Moreira, 2008; Royal College of Psychiatry, 2010). The concept encompasses a broad spectrum of behaviors, from less (e.g., superficial cuts, burns) to more severe, such as self-strangulation and overdose (Butler \& Malone, 2013; Favazza \& Rosenthal, 1993; Hawton et al., 2014; Walsh, 2007; Winchel \& Stanley, 1991).

Given the characteristics of prison settings, the availability of weapons is restricted in comparison with life in society, which affects the form of self-harm chosen by each prisoner. Regardless of the various types of self-harm behavior, for both sexes, the acts of cutting and scratching are the most common types (Hawton et al., 2014; Walsh, 2007). Additionally, the act of striking the head is becoming more frequent (Selling et al., 2014).

\footnotetext{
* Corresponding author.

E-mail address: martaasousaa@gmail.com (M. Sousa).

${ }^{1}$ Ana Rita Cruz is currently at the Faculty of Psychology and Education Sciences of the University of Porto
} 
The repetition of self-harm behaviors can be extremely dangerous and even lethal (Sakelliadis et al., 2010) with 50\% of prison-related suicides having a history of self-harm (Fazel, Cartwright, Norman-Nott, \& Hawton, 2008; Hawton et al., 2014). For example, in the 109 suicides between 2004 and 2009, in prisons in England and Wales, more than half occurred after a month of reported self-harm behaviors (Hawton et al., 2014), which suggests a temporal connection between self-harm and suicide.

Risk factors for self-harm behaviors can be organized into individual factors (e.g., being young, not having an affective relationship) (Hawton et al., 2014), and contextual factors. Prison characteristics, such as overcrowding, high turnover of prisoners between prisons, and a high level of security, are associated with higher suicide rates. These characteristics compromise the quality of the relationships between staff members and prisoners, contributing to an increase in inmates' anonymity and the risk of self-harm behaviors (Ginneken, Sutherland, \& Molleman, 2017).

In prison, the motives that may lead to the involvement in self-harm behaviors are also varied. Besides lethal motivation, other motivations underlying the perpetration of such acts have been studied (Butler \& Malone, 2013; Snow, 2002), such as situational (e.g., being in prison); related to the offense (e.g., being innocent); interpersonal (e.g., the concern with the family); instrumental (e.g., motivations related to the situation of being alone and wanting someone to talk); and to alleviate negative feelings (e.g., prisoners would prefer to hurt themselves rather than direct that anger towards others). In addition, studies with female prisoners identified two groups of individuals with distinct motivations: those who engage in these behaviors to relieve symptoms of anger, depression, and anxiety; and another group of women who develop selfharm behaviors in reaction to stressors or psychotic experiences (Coid, Wilkins, Coid, \& Everitt, 1992). Similar results were reported for male prisoners who referred that gaining emotional relief and externalizing anger were motivations to engage in behavior of this nature (Sakelliadis et al., 2010).

Nonetheless, in prison populations, self-harm behaviors, without suicidal intention, are often perceived as manipulative, which influence how prison staff responds to such acts (Ireland \& Quinn, 2007).

\subsection{Prison officers' attitudes}

Attitudes are complex elements of our personalities which encompasses a set of beliefs, feelings, and behavioral tendencies towards an event, object or individual group (Hogg \& Vaughan, 2005 cited in Cunha \& Gonçalves, 2017). Previous research shows that attitudes can influence behaviors (e.g., Ajzen, 1991). Thus, considering that attitudes reflect a tendency to act always in a similar way, studying attitudes allows us to predict an individual's response to a given situation, and consequently his/her social behavior (Ajzen \& Fishbein, 1980 cited in Higgins \& Ireland, 2009; Gonçalves \& Vieira, 2005; Neto, 2000).

In the criminal justice system, the attitudes of prison officers have been the subject of study considering that guards are essential elements in prisons, and their attitudes can influence their performance. Thus, Melvin, Gramling, and Gardner (1985) designed the "Attitudes towards prisoners" (ATP) scale in order to measure these attitudes. In their study, they examined ATP in six different samples (i.e., reform/rehabilitation groups, prisoners, students, community members, prison officers, and law enforcement officers) and found that, overall, prison officers had negative ATP.

Furthermore, some studies have sought to understand the influence of sociodemographic variables in prison officers' ATP, namely age, years of service, and academic level. For example, Gonçalves and Vieira (2005) demonstrated that older guards with more years of service have more positive ATP than younger guards with fewer years of service. In line with that, Kjelsberg and Loos (2008) also found that older officers view the prisoners as ordinary people, believing in their rehabilitation. The professional experience, according to the years of service, might promote the development of a more tolerant attitude towards prisoners, which may explain these results (Gonçalves \& Vieira, 2005). On the other hand, a higher academic level seems to be related to more negative ATP (Gonçalves \& Vieira, 2005).

About the prison officers' attitudes towards prisoners who self-harm (APSH), the only variable studied was gender. Ireland and Quinn (2007) demonstrated that women have more positive APSH (Ireland \& Quinn, 2007). In other words, women reported attitudes reflecting a greater understanding of self-harm (e.g., Self-harm is often an expression of profound emotional pain) and were less likely than men to agree with negative self-harm myths (e.g., Prisoners who self-harm do it purely for attention). A possible explanation for this relates to a potential increase in the ability of women to recognize others' feelings and experiences. Women tend to play a more important role in situations of extreme vulnerability, such as self-harm behaviors, where caring is an essential quality (Tait, 2008).

Some literature explores the existence of negative attitudes concerning the prisoners who engage in self-harm (e.g., Kenning et al., 2010; Short et al., 2009). Negative attitudes towards these prisoners are found when prison officers identify manipulation, as well as the attempt to call attention as reasons for the involvement in these behaviors. For authors, the lack of knowledge that prison officers demonstrate regarding the functions and causes of self-harm behavior might justify these negative attitudes (e.g., Kenning et al., 2010; Short et al., 2009). Besides, among these guards, there is a lack of willingness to help those who self-harm. Nonetheless, the literature also reports that prison officers who have negative attitudes feel that they do not have the competence to cope with these situations (Gough \& Hawkins, 2000; Ireland \& Quinn, 2007; Short et al., 2009).

The elements of the prison staff manifest a diversity of negative emotions (e.g., hostility) and stigmatizing attitudes when in contact with situations of self-harm, which associated with the absence of a structured intervention, increase inmates' risk to be (re)involved in more harmful behaviors (Marzano, Ciclitira, \& Adler, 2012; Taylor, Hawton, Fortune, \& Kapur, 2009).

However, positive and negative attitudes may arise about prisoners who self-harm depending on how guards interpret these acts. Classifying self-harm acts as "genuine" or "not genuine" influence prison officers' attitudes and feelings towards prisoners (Kenning et al., 2010; Ramluggun, 2013). For example, when perceiving behavior as non-genuine, female prisoners were seen by members of the prison guard as less deserving of support (Kenning et al., 2010). Relying solely on the severity of the act to interpret its genuineness is a dangerous approach since research shows that low severity is not always associated with low suicidal intent (Livingston, 1997 cited in Ireland, 2000), just as high severity does not always translate into high suicidal intent.

Besides, when prison staff members (including prison officers) assessed the act as genuine, either because of mental problems or external problems, they felt that they should provide support (Short et al., 2009). They believed that prisoners (female in this case) would not be able to stop these behaviors alone or that those problems might be sufficiently severe to deserve support. Furthermore, positive attitudes towards these prisoners also seem to depend on attitudes towards prisoners in general. A positive correlation was found between the attitudes towards imprisonment and prisoners in general, and prisoners that engage in self-harm behaviors (Ireland \& Quinn, 2007). Guards that believed in the importance of treatment for the prison population and with more empathic traits demonstrated more positive attitudes towards self-harming prisoners.

Considering the nature of prison officers' work, they have direct and frequent contact with prisoners and are fundamental in the identification and management of risk (Liebling \& Krarup, 1993; Short et al., 2009). The nature of their relationships with prisoners can facilitate the process of sharing and communicating problems and feelings, which is assumed to be preventive and therapeutic, and therefore central to 
controlling self-harm and suicide rates (Pannell, Howells, \& Day, 2003). Thus, it is imperative to assess prison officers' attitudes towards this phenomenon, since the attitudes predispose our behavior and in this case, may influence the performance of prison officers. Furthermore, Pannell et al. (2003) have found that the way prison officers look at the functions and causes of self-harm is not influenced either by severity or repetition of these acts, which is worrying.

\subsection{Goal}

In this study, we aimed to explore the attitudes of Portuguese prison officers regarding self-harm perpetrated by prisoners, exploring the influence of sociodemographic variables on these attitudes. For this purpose, we used the "attitudes towards prisoners who self-harm" scale (APSH). Considering the literature, we explore as secondary objective the influence between APSH and ATP.

We predicted that there would be gender differences with female guards having more positive attitudes towards self-harm prisoners than male guards. We also predicted based on the influence of these variables on the ATP that there will be differences in attitudes taking into account age and years of service with older guards and those with more years of service to have the most positive attitudes towards self-harm in prisoners. Moreover, we anticipate that there will be academic level differences with the guards with the highest academic degree to reveal the most negative attitudes. Finally, we predict a relationship between ATP and APSH. Additionally, we want to understand the influence of an additional variable, namely the marital status in these attitudes.

\section{Materials and methods}

\subsection{Participants}

The participants in this study were selected according to a convenience sampling process. The sample consisted of 176 prison officers, $137(77.80 \%)$ male and $39(22.20 \%)$ female, which represents the normal distribution of the sexes in this professional activity. The participants were recruited from three prisons in the north of Portugal. The prison officers' average age was $42.75(S D=8.79)$ years, ranging between 24 and 63 years. The years of service $(n=173)$ ranged from 1 to 38 years $(M=17.63, S D=9.53$ ) (see Table 1 ).

More than half of the prison officers $(63.60 \%, n=173)$ are in an intimate relationship, and the majority $(70.50 \%, n=173)$ have secondary education. From the group of guards with a college degree (13.90\%, $n=24)$, $25 \%$ graduated in education-related courses.

Table 1

Age and years of service by class of standard deviations by gender.

\begin{tabular}{ll} 
Men & Woman \\
\hline$n(\%)$ & $n(\%)$
\end{tabular}

\begin{tabular}{lll}
\hline Age & & \\
$<32$ years & $26(19.00 \%)$ & - \\
$32-40$ years & $19(13.90 \%)$ & $18(46.20 \%)$ \\
$41-49$ years & $61(44.50 \%)$ & $18(46.20 \%)$ \\
$>49$ years & $31(22.60 \%)$ & $3(7.70 \%)$ \\
Total & $137(100.00 \%)$ & $39(100.00 \%)$ \\
Years of service & & - \\
$<10$ years & $29(21.60 \%)$ & $23(59.00 \%)$ \\
$10-19$ years & $42(31.30 \%)$ & $15(38.50 \%)$ \\
$20-29$ years & $45(33.60 \%)$ & $1(2.60 \%)$ \\
$>29$ years & $18(13.40 \%)$ & $39(100.0 \%)$ \\
Total & $134(100.0 \%)$ & \\
\hline
\end{tabular}

\subsection{Instruments}

2.2.1. Attitudes towards prisoners who self-harm scale (APSH) (Ireland \& Quinn, 2007)

This instrument has 15 items, and individuals should answer on a scale that ranks from 1 (completely disagree) to 5 (completely agree). Previous factor analysis identified four factors: "Attitudes endorsing harsh treatment" that encompasses four items (e.g., The best way to help those who self-harm is to ignore them); "Attitudes reflecting understanding" consisting of six items (e.g., Self-harm is often an expression of profound emotional pain); "Attitudes endorsing negative myths", consisting of three items (e.g., Self-harming is something to be ashamed of), and finally, the "Relating self-harm to suicide" factor, comprising two items (e.g., Self-harm is a failed suicide attempt). Cronbach's alphas of these four factors are $0.75,0.62,0.71$ and 0.58 , respectively; the scale total alpha was 0.74 (Ireland \& Quinn, 2007).

\subsubsection{Attitudes towards prisoners scale (ATP) (Gonçalves \& Vieira, 2007;} Melvin et al., 1985)

The Portuguese version of the instrument comprises 34 items, on which individuals answer according to a 5-point Likert scale from 1 (strongly disagree) to 5 (strongly agree). The statements refer to general questions about the prison population (e.g., "Prisoners are different from most people") and personal issues (e.g., "I would never want one of my children dating an ex-prisoner").

The scale is has one dimension and showed good internal consistency with an alpha of 0.91 in a sample of Portuguese prison officers (Gonçalves \& Vieira, 2007).

\subsection{Procedure}

The authors of the "Attitudes towards prisoners who self-harm" scale (Ireland \& Quinn, 2007) and the "Attitudes towards prisoners" scale (Gonçalves \& Vieira, 2007) were contacted and authorized the use of the scales. After consent, the "Attitudes towards prisoners who selfharm" scale was submitted to a translation and back translation process by four investigators. The study was approved by the Ethics Committee of the University of Minho and had authorization from the Portuguese Prison Services.

After obtaining permission from the Portuguese Prison Services to conduct this research, we contacted three prisons in the north of the country. Then, through articulation with the Commissioner or the Chief, it was defined how the instruments would be applied to minimize any potential disruption of institutional functioning. The scales, the sociodemographic questionnaire, and informed consents were distributed to prison officers in paper format at their work points. The prison officers signed the informed consent, and they completed the two scales individually.

\subsection{Data analysis}

We have performed a confirmatory factor analysis on "Attitudes towards prisoners who self-harm" scale using the version 23.0 of the IBM $^{\circledast}$ SPSS $^{\circledast}$ software (Statistical Package for the Social Sciences) and the AMOS software. The results of this analysis were not satisfactory (cf. Garbutt \& Casey, 2015), since we had alphas of 0.59, 0.10, 0.37 and -0.63 , in the scale factors and a total alpha of 0.30 . We tried to achieve better alphas by removing some items, however, there were no significant improvements. Therefore, we opted to explore individual items according to the four original factors of the scale. Our data were organized according to each factor and results were based on the descriptive analysis (counts and percentages) of the individual responses. We recoded each item response and considered a negative evaluation of the item if the answer was "disagree" and "strongly disagree", a positive assessment would consist of the "agree" and "strongly agree" responses and, finally, the uncertainty corresponded to the item "neither agree 
nor disagree". Then, we tested for the possible influences of sociodemographic variables namely gender, age, education, marital status, and years of service in the responses to the scale.

Considering some items from the "attitudes towards prisoners" scale that are relevant from a theoretical point of view, we also analyzed the correlations between the items of the two scales.

The variables age and years of service were recoded and organized by standard deviation classes, obtaining four classes each: for age, $<$ $32,32-40,41-49$, and $>49$ years old, and for years of service, $<10$, $10-19,20-29$, and $>29$ years. Regarding the variable level of education, since the number of prison officers with the 4th, sixth and ninth years was much lower than the rest of the categories, we chose to recode them in a new category: "9th or less". The same happened with the variable marital status, was recoded as "with an affective relationship" and "without affective relation".

Since normality of the distributions and homogeneity of the variances were not met, we ran non-parametric tests for comparison of means and association tests between items.

\section{Results}

\subsection{Attitudes towards prisoners who self-harm}

\subsubsection{Attitudes endorsing harsh treatment}

Regarding attitudes towards harsh treatment, the majority of our sample did not consider the treatment of the prisoners who self-harm a waste of time or expense of resources. At the same time, they do not believe that the best way to treat those who self-harm is by restricting or ignoring the individual (see Table 2).

Prison officers' responses were influenced by sociodemographic variables, namely age and years of service. Regarding age, we found significant differences in the responses given to the item "The only way to stop persistent self-harming is to restrain the individual", $\left(\chi^{2}\right.$ (3) $=12.73, p<.01$. Mann-Whitney tests with Bonferroni correction showed differences between the group " $<32$ years" and "41-49 years", $\mathrm{U}=677.50, p=.006$, as well as between the group "32-40 years" and "41-49 years", $\mathrm{U}=980.00, p=.005$. Thus, considering the mean rank, we found that the differences were among participants aged $41-49$. The guards aged 41 to 49 tend to disagree more against restrainment. Additionally, significant differences were found in this item considering the variable years of service, $\left(\chi^{2}\right.$ (3) $=8.34, p<.05$ ), with guards with $>29$ years of service considering more the individual restrain as an option for self-harming individual than the others.

\subsubsection{Attitudes reflecting understanding}

Most prison officers do not have an opinion about some of the commonly reported reasons for self-harming, such as "Many prisoners who self-harm have suffered some kind of abuse" or "Self-harming behavior is often about the prisoners regaining a sense of control" (see Table 3). However, significant differences were found between men and women in the responses given to the item "Many prisoners who selfharm have suffered from some kind of abuse", $\mathrm{U}=1994.0, p<.05$. Male guards demonstrated a stronger belief that prisoners who commit self-harm had some kind of abuse in their history (34.3\%) in comparison to female guards (15.4\%).

On the other hand, the majority of our sample believed that selfharm behavior might be a coping mechanism (see Table 3 ) and at the same time, most of the guards did not consider that prisoners intend to punish themselves with these behaviors.

At last, some prison officers $(43.8 \%)$ report that they are not disturbed to see somebody self-harm (see Table 3).

\subsubsection{Attitudes endorsing negative myths}

Regarding the items that represent the myths about self-harm, the majority of prison officers believed that prisoners engage in these behaviors to attract attention and manipulate those around them (see Table 4). However, there was a division in their evaluation of self-harm being something to be ashamed of (see Table 4).

Concerning the ideas around manipulative motives, there were statistically significant differences in the responses to the item as a function of sex $(U=1972.5, p<.01)$. The female guards believed more in manipulative motives for prisoners to engage in self-harm behaviors $(66.7 \%)$ than male guards $(42.3 \%)$.

\subsubsection{Relating self-harm to suicide}

Most prison officers do not believe that self-harm behavior represents a failed suicide attempt as well as those whom self-harm will commit suicide (see Table 5).

After testing for the influence of the variable age, we found significant differences to the item "Self-harm is a failed suicide attempt, $\left(\chi^{2}(3)=8.90, p<.05\right)$ ". Mann-Whitney tests with Bonferroni correction showed differences between the group " $<32$ years" and "32-40 years", $\mathrm{U}=303.00, p<.006$. Analyzing the mean rank, we noticed that prison officers, between the ages of 32 and 40, did not considerate that self-harm as a failed suicide attempt, by comparison with the other guards.

\subsection{Attitudes towards prisoners and attitudes towards prisoners who self-} harm

In this section, we have tested the association between guards general attitudes towards prisoners and their particular attitudes towards prisoners who self-harm. We have found a positive and significant correlation between the ability to understand prisoners' feelings and the understanding of prisoners who perpetrate self-harm (see Table 6). For example, prison officers who agreed with the item that states that prisoners have and experience feelings, similarly to nonprisoners, also agreed that self-harm is often the expression of deep emotional pain.

Prison officers who considered that prisoners have feelings like the rest of us and also agreed with the idea that they have a potential of rehabilitation, and did not believe that ignoring prisoners that commit self-harm or endorsing in harsh practices were the best treatment approaches (see Table 7).

On the contrary, guards who agreed that prisoners must be severely and strictly disciplined, also agreed that the best way to help those who self-harm is to ignore these individuals. In line with the previous association, our results also suggest that when prison officers considered that prisoners never change and only respect brute force, they also

Table 2

Descriptive analysis of items related to attitudes involving more harsh treatments.

\begin{tabular}{|c|c|c|c|}
\hline & Negative assessment & Uncertainty & Positive assessment \\
\hline The best way to help those who self-harm is to ignore them. & $71.6 \%$ & $15.3 \%$ & $12 \%$ \\
\hline Treating prisoners who self-harm is a waste of time. & $69.8 \%$ & $22.2 \%$ & $7.4 \%$ \\
\hline The treatment of self-harming prisoners is a drain on resources. & $63.7 \%$ & $20.5 \%$ & $15.9 \%$ \\
\hline The only way to stop persistent self-harming is to restrain the individual. ${ }^{\mathrm{a}, \mathrm{b}}$ & $51.7 \%$ & $23.3 \%$ & $24.4 \%$ \\
\hline
\end{tabular}

\footnotetext{
${ }^{\mathrm{a}} p<.01$ in terms of age of prison officers.

$p<.05$ in terms of years of service of prison officers.
} 
Table 3

Descriptive analysis of the items referring to attitudes that reflect understanding.

\begin{tabular}{|c|c|c|c|}
\hline & Negative assessment & Uncertainty & Positive assessment \\
\hline Self-harm is often an expression of profound emotional pain. & $26.7 \%$ & $35.2 \%$ & $38.0 \%$ \\
\hline Engaging in self-harm often serves as a coping mechanism. & $13.6 \%$ & $23.9 \%$ & $61.3 \%$ \\
\hline Many prisoners who self-harm have suffered from some kind of abuse. ${ }^{a}$ & $31.8 \%$ & $37.5 \%$ & $30.1 \%$ \\
\hline Self-harming behavior is often about the prisoner regaining a sense of control. & $33.5 \%$ & $43.2 \%$ & $22.7 \%$ \\
\hline Prisoners who self-harm want to punish themselves. & $64.3 \%$ & $27.3 \%$ & $6.8 \%$ \\
\hline Seeing somebody self-harm is something which disturbs me. & $43.8 \%$ & $24.4 \%$ & $30.7 \%$ \\
\hline
\end{tabular}

${ }^{\mathrm{a}} p<.05$ in terms of gender of prison officers.

Table 4

Descriptive analysis of items concerning attitudes involving negative myths.

\begin{tabular}{|c|c|c|c|}
\hline & Negative assessment & Uncertainty & Positive assessment \\
\hline Self-harming is something to be ashamed of. & $40.3 \%$ & $33.5 \%$ & $26.1 \%$ \\
\hline Prisoners who self-harm do it purely for attention. & $10.9 \%$ & $14.8 \%$ & $73.8 \%$ \\
\hline Prisoners self-harm primarily to manipulate others. ${ }^{a}$ & $27.2 \%$ & $25 \%$ & $47.8 \%$ \\
\hline
\end{tabular}

${ }^{a} p<.01$ in terms of gender of prison officers.

believed that prisoners engage in self-harm behaviors only for attention and manipulative intention (see Table 8).

\section{Discussion}

Our study aimed to explore the attitudes of a sample of Portuguese prison officers towards prisoners who self-harm, analyzing the influence of sociodemographic variables on the formation of these attitudes. Moreover, as a secondary goal, we explored the influence between attitudes towards prisoners who self-harm and attitudes towards prisoners.

The results show that the majority of prison officers do not advocate harsh treatment for self-harming prisoners. For example, they do not consider treatment as an expense of resources or time, which is positive, considering their role in supporting and responding to these behaviors. Our results lead us to advocate for the pertinence of working with prison officers in order to raise awareness of their importance as firstline responders. Since prison officers are, from all the prison staff members, those who have more contact with prisoners, they are crucial elements in identifying and accompanying individuals at risk (Liebling \& Krarup, 1993; Short et al., 2009). Their working hours and time spent inside prison allow them to observe the behavior of prisoners and to notice changes in behaviors that may be warning signs. At the same time, they can intervene with prisoners in a psychoeducational way, teaching them through informal conversations about how to deal with crises.

However, our results suggest that prison officers may lack the knowledge regarding the causes and functions of self-harming acts (Gough \& Hawkins, 2000; Kenning et al., 2010; Short et al., 2009). Being unaware of the causes and functions of self-harm possibly explains the lack of opinion about these issues, as well as the defense of some myths. These results are in agreement with the literature, which tells us that prison officers look at these behaviors as intentional acts, aiming to attract attention, control the environment around them and obtain benefits (Kenning et al., 2010). The prevalence of the manipulative belief among prison officers suggests that some agree that prisoners might only perpetrate self-harm not because they are suffering, but for instrumental reasons (Gough \& Hawkins, 2000; Kenning et al., 2010; Short et al., 2009), which in turn might influence the way they deliver support and respond to a self-harm situation.

Repeated exposure to self-harm behaviors may explain why prison officers report not to be disturbed by exposure to these behaviors, in line with previous studies that showed that over time guards may become more desensitized to self-harm behaviors (Kenning et al., 2010; Walker et al., 2017).

Our results also suggest that the attitudes guards have towards the prison population influence their responses regarding prisoners who self-harm. Specifically, those who believe in the rehabilitation of prisoners and agree with the statement that says that prisoners have feelings like the general population do not advocate harsh treatment with these prisoners in particular. These guards also tend to demonstrate an empathic understanding of the reasons most often cited for the involvement in self-harm, namely that it is often an expression of deep emotional pain and that many prisoners who self-harm have suffered from some kind of abuse. However, those who advocate more treatment punitive practices about prisoners in general, also advocate the same approach for those who self-harm. The professional activity of prison officer might be culturally based on traditional male qualities such as authority, aggressiveness, and dominance. These values may influence how guards interact with prisoners and might explain why many officers demonstrate no interest and indifference regarding prisoners who commit self-harm (Crawley \& Crawley, 2008). This traditionally male culture may also influence the acceptance of more punitive practices and, consequently, the devaluing of the importance of intervention initiatives with self-harming prisoners.

Our data also suggest that most prison officers do not believe that self-harming behavior can lead to suicide. Accordingly, previous studies reported that prison officers only considered the positive association between self-harm and suicide when the behavior was viewed as severe (Pannell et al., 2003). However, low severity might not translate into low suicidal intent (Livingston, 1997, cited in Ireland, 2000), and the opposite is also valid. It should be noted that some studies dichotomize

Table 5

Descriptive analysis of the items referring to the attitudes that relate self-harm to suicide.

\begin{tabular}{|c|c|c|c|}
\hline & Negative assessment & Uncertainty & Positive assessment \\
\hline Self-harm is a failed suicide attempt. ${ }^{\mathrm{a}}$ & $82.4 \%$ & $11.4 \%$ & $6.3 \%$ \\
\hline Prisoners who self-harm will usually go on to commit suicide. & $81.9 \%$ & $14.8 \%$ & $2.8 \%$ \\
\hline
\end{tabular}

${ }^{\mathrm{a}} p<.05$ in terms of age of prison officers. 
Table 6

Spearman correlation between items referring to attitudes that reflect understanding and ATP items.

\begin{tabular}{|c|c|c|c|}
\hline Attitudes reflecting understanding & $\begin{array}{l}\text { Most prisoners are victims of circumstance and } \\
\text { deserve to be helped. }\end{array}$ & $\begin{array}{l}\text { Prisoners have feelings like the } \\
\text { rest of us. }\end{array}$ & $\begin{array}{l}\text { Most prisoners have the capacity } \\
\text { for love. }\end{array}$ \\
\hline $\begin{array}{l}\text { Self-harm is often an expression of profound } \\
\text { emotional pain. }\end{array}$ & $r_{\mathrm{s}}=0.29^{* *}$ & $r_{\mathrm{s}}=0.32^{* *}$ & $r_{\mathrm{s}}=0.26^{* *}$ \\
\hline $\begin{array}{l}\text { Many prisoners who self-harm have suffered from } \\
\text { some kind of abuse. }\end{array}$ & $r_{\mathrm{s}}=0.21^{* * *}$ & $r_{\mathrm{s}}=0.05$ & $r_{\mathrm{s}}=0.18^{*}$ \\
\hline
\end{tabular}

** $p<.01$

${ }^{*} p<.05$.

these prisoners between "manipulators" and those who attempt to commit suicide, demonstrating that these groups are not mutually exclusive (Dear, Thomson, \& Hills, 2000). In this way, these results are relevant and it is, therefore, essential to provide training to these professionals, to avoid possible misinterpretations of behaviors like these, that could interfere in guards' responses and prisoners' future behaviors.

In our study, sociodemographic variables (e.g., education, age, years of service, marital status), contrary to the literature, were not significantly related to the guards' attitudes. The gender distribution might have influenced some results in our sample ( $n$ male $=137 ; n$ female $=39$ ). It was not possible to obtain the same sample size of men and women guards, but our sample represents the current distribution of the sexes in this profession. Also, we should consider that different countries might have different training programs for prison officers.

It is also essential to consider that about two-thirds of the sample $(70.5 \%)$ have secondary education, which can contribute to the lack of differences concerning this variable since the groups in comparison do not have a similar sample number. However, we must bear in mind that since 2007 (Dec. Law no. 391- C /, 2007 of 24 December), in Portugal, the minimum level of education to access the prison officer career is precisely the secondary education, which means that in the short term, with the retirement of the older guards, there will no longer exist variations at the academic level that allows us to study the possible influence of this variable. In the short term, there will be a general increase in the academic level compared to what exists today.

An additional aspect to discuss relates to the influence of marital status. The literature demonstrates that marriage can lead to the acquisition of new social and family roles, responsibilities and emotional support that, consequently, could increase tolerance and provide adequate resources to deal with the stressors associated with the profession (Finn, 2000; Hernández-Martín, Fernández-Calvo, Ramos, \& Contador, 2006; Kurtz, 2008). Thus, positive attitudes of married prison officers may arise by the social bond that can be created through marriage (Sampson, Laub, \& Wimer, 2006; Schaie \& Willis, 2003 cited in Cunha \& Gonçalves, 2017) and influence their attitudes towards prisoners that perpetrate self-harm. However, this did not happen. It is also important to mention that the support provided by the partners can be the determining factor in the greater tolerance in performing their functions rather than the social bond created with the marriage. Thus, family support may be replaced by other extra-work activities, for example, physical exercise.
A longer experience of service increases the probability of contacting these self-harm behaviors, which might relate to the development of more tolerant attitudes towards these prisoners (Gonçalves \& Vieira, 2005). However, in our study, it was not possible to control the amount of contact that this group of professionals had with self-harm prisoners. This amount of contact with self-harming behaviors, rather than age and years of service, might be a striking element in the formation of attitudes.

\subsection{Limitations and research orientations}

The study has some limitations, namely, the poor results from the confirmatory factor analysis we performed on the attitudes towards prisoners who self-harm scale. It would be important to increase the sample size and include a national sample of prison officers.

Regarding sociodemographic variables, future studies should consider the gender of the prisoner who self-harm, since it appears to be a more important variable than the prison officers' gender (Tait, 2008). Moreover, future research should also analyze the influence of being a male or female guard in a female or male prison.

Furthermore, it would be essential to test if the area of academic training, more than years of education, influence prison officers' attitudes and if the personal and social extra work occupations more than marital status influence the formation of the attitudes.

Future studies also should adopt qualitative methods, such as interviews, to explore the prison culture and perceive its influence in guards' attitudes. It would also be relevant to consider guards' perceptions concerning the importance of their role as first-line responders, as well as explore their prior contact with self-harm behaviors and how those variables might influence their perceptions. However, it should be noted that attitudes do not directly translate into behaviors and competence, and professionalism exerts influence in this connection (Crewe, Liebling, \& Hulley, 2011). Consequently, it would be relevant to assess the relationship between attitudes and behaviors, contrasting prison officers' attitudes and behaviors in the face of stressful situations such as self-harm.

Lastly, it would be essential to study the actual prevalence of selfharm acts in Portuguese prisons to know the dimension of the problem.

Table 7

Spearman correlation between items referring to attitudes that reflect the harder treatments and ATP items.

\begin{tabular}{|c|c|c|c|}
\hline Attitudes endorsing harsh treatment & $\begin{array}{l}\text { Prisoners have feelings like the rest } \\
\text { of us. }\end{array}$ & $\begin{array}{l}\text { Prisoners need affection and praise just like } \\
\text { anybody else. }\end{array}$ & Most prisoners can be rehabilitated. \\
\hline $\begin{array}{l}\text { The best way to help those who self-harm is to ignore } \\
\text { them. }\end{array}$ & $r_{\mathrm{s}}=-0.30^{* *}$ & $r_{\mathrm{s}}=-0.25^{* *}$ & $r_{\mathrm{s}}=-0.20^{* *}$ \\
\hline Treating prisoners who self-harm is a waste of time. & $r_{\mathrm{s}}=-0.22^{* *}$ & $r_{\mathrm{s}}=-0.20^{* *}$ & $r_{\mathrm{s}}=-0.20^{* *}$ \\
\hline $\begin{array}{l}\text { The treatment of self-harming prisoners is a drain on } \\
\text { resources. }\end{array}$ & $r_{\mathrm{s}}=-0.29^{* *}$ & $r_{\mathrm{s}}=-0.17^{*}$ & $r_{\mathrm{s}}=-0.17^{*}$ \\
\hline
\end{tabular}




\subsection{Conclusion}

Prison officer staff demonstrated some difficulties in understanding self-harm among prisoners, highlighting the negative myths that exist in the literature, as well as neglecting the fact that these behaviors may, in some cases, culminate in suicide.

The lack of knowledge of these agents about self-harm may justify some of the results of this study (Gough \& Hawkins, 2000; Kenning et al., 2010; Short et al., 2009). Guards tend to agree on the manipulative intention and need for attention behind those actions, considering that they are a way for prisoners to obtain benefits (Kenning et al., 2010).

\subsection{Implications for practice}

These results highlight the need for specific training about this phenomenon, not only in prison officers initial training but also in continuing training, identifying issues of particular importance to address, such as interpersonal skills and behavioral strategies to deal with incarcerated individuals who self-harm (Sweeney, Clarbour, \& Oliver, 2018). This will contribute to minimize the development and impact of negative myths and allow for a more efficient intervention in the everyday challenges of prison settings.

\section{Funding}

This work was supported by the Portuguese Ministry of Science, Technology and Higher Education through national funds and co-financed by FEDER and COMPETE2020 under the PT2020 Partnership Agreement (POCI-01-0145-FEDER-007653) - Psychology Research Centre (UID/PSI/01662), awarded to Ana Rita Cruz. The study was also supported by Grant SFRH/BPD/108602/2015 from the Portuguese Foundation for Science and Technology awarded to Andreia de Castro Rodrigues.

\section{Declaration of Competing interest}

None.

\section{References}

Ajzen, I. (1991). The theory of planned behavior. Organizational Behavior and Human Decision Processes, 50(2), 179-211. https://doi.org/10.1016/0749-5978(91)90020-T.

Butler, A. M., \& Malone, K. (2013). Attempted suicide v. non-suicidal self-injury: Behaviour syndrome or diagnosis? British Journal of Psychiatry, 202(5), 324-325. https://doi.org/10.1192/bjp.bp.112.113506.

Carli, V., Mandelli, L., Poštuvan, V., Roy, A., Bevilacqua, L., Cesaro, C., ... Sarchiapone, M. (2011). Self-harm in prisoners. CNS Spectrums, 16(3), 75-81. https://doi.org/10. 1017/S1092852912000211.

Coid, J., Wilkins, J., Coid, B., \& Everitt, B. (1992). Self-mutilation in female remanded prisoners II: A cluster analytic approach towards identification of a behavioural syndrome. Criminal Behaviour and Mental Health, 2(1), 1-14. https://doi.org/10. 1002/cbm.1992.2.1.1.

Cooper, J., Kapur, N., Webb, R., Lawlor, M., Guthrie, E., Mackway-Jones, K., \& Appleby, L. (2005). Suicide after deliberate self-harm: A 4-year cohort study. American Journal of Psychiatry, 162(2), 297-303. https://doi.org/10.1176/appi.ajp.162.2.297.

Crawley, E., \& Crawley, P. (2008). Understanding prison officers: Culture, cohesion and conflict. In J. Bennett, B. Crewe, \& A. Wahidin (Eds.). Understanding prison staff (pp. 134-152). Devon: Willan Publishing.

Crewe, B., Liebling, A., \& Hulley, S. (2011). Staff culture, use of authority and prisoner quality of life in public and private sector prisons. Australian \& New Zealand Journal of Criminology, 44(1), 94-115. https://doi.org/10.1177/0004865810392681.

Cunha, O. S., \& Gonçalves, R. A. (2017). Attitudes of police officers toward offenders: Implications for future training. Policing: An International Journal of Police Strategies \& Management, 40(2), 265-277. https://doi.org/10.1108/PIJPSM-02-2016-0013.

Daggett, D. M., \& Camp, S. D. (2009). Do official misconduct data tell the same story as the individuals who live in prison? Criminal Justice Review, 34(3), 428-449. https:// doi.org/10.1177/0734016808329291.

Dear, G. E., Thomson, D. M., \& Hills, A. M. (2000). Self-harm in prison: Manipulators can also be suicide attempters. Criminal Justice and Behavior, 27(2), 160-175. https://doi. org/10.1177/0093854800027002002.

Dec. Law no. 391- C (2007, 24 December). Diário da República nº 247/2007, $2^{\circ}$ Suplemento, Série I. Lisboa: Ministério da Justiça. 
Favazza, A. R., \& Rosenthal, R. J. (1993). Diagnostic issues in self-mutilation. Psychiatric Services, 44(2), 134-140. https://doi.org/10.1176/ps.44.2.134.

Fazel, S., Cartwright, J., Norman-Nott, A., \& Hawton, K. (2008). Suicide in prisoners: A systematic review of risk factors. The Journal of Clinical Psychiatry, 69(11), 1721-1731. https://doi.org/10.4088/JCP.v69n1107.

Finn, P. (2000). Addressing correctional officer stress: Programs and strategies. Washington, DC: US Department of Justice, Office of Justice Programs, National Institute of Justice.

Garbutt, K., \& Casey, H. (2015). Attitudes towards prisoners who self harm scale: A psychometric evaluation. Journal of Aggression, Conflict and Peace Research, 7(3), 158-166. https://doi.org/10.1108/JACPR-08-2014-0133.

Ginneken, E. F., Sutherland, A., \& Molleman, T. (2017). An ecological analysis of prison overcrowding and suicide rates in England and Wales, 2000-2014. International Journal of Law and Psychiatry, 50, 76-82. https://doi.org/10.1016/j.ijlp.2016.05.005.

Gonçalves, R. A., \& Vieira, S. (2005). Atitudes face aos reclusos em guardas prisionais: Implicações para a formação do pessoal penitenciário [Attitudes towards prisoners in prison officers: Implications for the training of prison staff]. Temas Penitenciários, III (1-2), 23-28.

Gonçalves, R. A., \& Vieira, S. (2007). Actitudes hacia los reclusos en guardias de prisiones: Validación de una escala y implicaciones para la formación del personal penitenciario. [Attitudes towards prisoners in prison officers: Validation of a scale and implications for the training of prison staff]. In R. Arce, F. Fariña, E. Alfaro, C. Civera, \& F. Tortosa (Eds.). Psicología juridica: Evaluación y intervención (pp. 263-269). Valencia: Diputació de València.

Gough, K., \& Hawkins, A. (2000). Staff attitudes to self-harm and its management in a forensic psychiatric service. The British Journal of Forensic Practice, 2(4), 22-28. https://doi.org/10.1108/14636646200000030.

Hawton, K., Linsell, L., Adeniji, T., Sariaslan, A., \& Fazel, S. (2014). Self-harm in prisons in England and Wales: An epidemiological study of prevalence, risk factors, clustering, and subsequent suicide. The Lancet, 383(9923), 1147-1154. https://doi.org/ 10.1016/S0140-6736(13)62118-2.

Hernández-Martín, L., Fernández-Calvo, B., Ramos, F., \& Contador, I. (2006). El síndrome de burnout en funcionarios de vigilancia de un centro penitenciario [Burnout in correctional officers at a penitentiary institution]. International Journal of Clinical and Health Psychology, 6(3), 599-611.

Higgins, C., \& Ireland, C. (2009). Attitudes towards male and female sex offenders: A comparison of forensic staff, prison officers and the general public in Northern Ireland. The British Journal of Forensic Practice, 11(1), 14-19. https://doi.org/10. 1108/14636646200900004.

Ireland, J. L. (2000). A descriptive analysis of self-harm reports among a sample of incarcerated adolescent males. Journal of Adolescence, 23(5), 605-613. https://doi.org/ 10.1006/jado.2000.0347.

Ireland, J. L., \& Quinn, K. (2007). Officer attitudes towards adult male prisoners who selfharm: Development of an attitudinal measure and investigation of sex differences. Aggressive Behavior, 33(1), 63-72. https://doi.org/10.1002/ab.20168.

Kenning, C., Cooper, J., Short, V., Shaw, J., Abel, K., \& Chew-Graham, C. (2010). Prison staff and women prisoner's views on self-harm; their implications for service delivery and development: A qualitative study. Criminal Behaviour and Mental Health, 20(4), 274-284. https://doi.org/10.1002/cbm.777.

Kjelsberg, E., \& Loos, L. H. (2008). Conciliation or condemnation? Prison employees' and young peoples' attitudes towards sexual offenders. International Journal of Forensic Mental Health, 7(1), 95-103. https://doi.org/10.1080/14999013.2008.9914406.

Kurtz, D. L. (2008). Controlled burn: The gendering of stress and burnout in modern policing. Feminist Criminology, 3(3), 216-223. https://doi.org/10.1177/ 1557085108321672.

Liebling, A., \& Krarup, H. (1993). Suicide attempts and self-injury in male prisons. London: Home Office Research Planning Unit.

Lohner, J., \& Konrad, N. (2006). Deliberate self-harm and suicide attempt in custody: Distinguishing features in male inmates' self-injurious behavior. International Journal of Law and Psychiatry, 29(5), 370-385. https://doi.org/10.1016/j.jilp.2006.03.004.

Marzano, L., Ciclitira, K., \& Adler, J. (2012). The impact of prison staff responses on selfharming behaviours: Prisoners' perspectives. British Journal of Clinical Psychology,
51(1), 4-18. https://doi.org/10.1111/j.2044-8260.2010.02007.x.

Melvin, K. B., Gramling, L. K., \& Gardner, W. M. (1985). A scale to measure attitudes toward prisoners. Criminal Justice and Behavior, 12(2), 241-253. https://doi.org/10. $1177 / 0093854885012002006$.

Moreira, N. A. C. (2008). Sofrimento, desespero e comportamentos suicidários na prisão [Suffering, despair and suicidal behavior in prison]. Coimbra, Portugal: Quarteto.

Neto, F. (2000). Psicologia social [Social psychology]. Vol. II)Lisboa, Portugal: Universidade Aberta.

Pannell, J., Howells, K., \& Day, A. (2003). Prison officer's beliefs regarding self-harm in prisoners: An empirical investigation. International Journal of Forensic Psychology, 1(1), 103-110.

Ramluggun, P. (2013). A critical exploration of the management of self-harm in a male custodial setting: Qualitative findings of a comparative analysis of prison staff views on self-harm. Journal of Forensic Nursing, 9(1), 23-34. https://doi.org/10.1097/JFN 0b013e31827a5984.

Royal College of Psychiatry (2010). Self-harm, suicide and risk: Helping people who self-harm college report CR158. London: Royal College of Psychiatrists.

Sakelliadis, E. I., Papadodima, S. A., Sergentanis, T. N., Giotakos, O., \& Spiliopoulou, C. A. (2010). Self-injurious behavior among Greek male prisoners: Prevalence and risk factors. European Psychiatry, 25(3), 151-158. https://doi.org/10.1016/j.eurpsy.2009. 07.014 .

Sampson, R. J., Laub, J. H., \& Wimer, C. (2006). Does marriage reduce crime? A counterfactual approach to within-individual causal effects. Criminology, 44(3), 465-508. https://doi.org/10.1111/j.1745-9125.2006.00055.x.

Selling, D., Solimo, A., Lee, D., Horne, K., Panove, E., \& Venters, H. (2014). Surveillance of suicidal and nonsuicidal self-injury in the new York City jail system. Journal of Correctional Health Care, 20(2), 163-167. https://doi.org/10.1177/ 1078345813518637.

Short, V., Cooper, J., Shaw, J., Kenning, C., Abel, K., \& Chew-Graham, C. (2009). Custody vs care: Attitudes of prison staff to self-harm in women prisoners-A qualitative study. The Journal of Forensic Psychiatry \& Psychology, 20(3), 408-426. https://doi. org/10.1080/14789940802377114.

Snow, L. (2002). Prisoners' motives for self-injury and attempted suicide. The British Journal of Forensic Practice, 4(4), 18-29. https://doi.org/10.1108/ 14636646200200023.

Sweeney, F., Clarbour, J., \& Oliver, A. (2018). Prison officers' experiences of working with adult male offenders who engage in suicide-related behaviour. The Journal of Forensic Psychiatry \& Psychology, 29(3), 467-482. https://doi.org/10.1080/ 14789949.2017.1421248.

Tait, S. (2008). Prison officers and gender. In J. Bennett, B. Crewe, \& A. Wahidin (Eds.) Understanding Prison Staff (pp. 65-91). Devon: Willan Publishing.

Taylor, T. L., Hawton, K., Fortune, S., \& Kapur, N. (2009). Attitudes towards clinical services among people who self-harm: Systematic review. The British Journal of Psychiatry, 194(2), 104-110. https://doi.org/10.1192/bjp.bp.107.046425.

Walker, T., Shaw, J., Hamilton, L., Turpin, C., Reid, C., \& Abel, K. (2017). "Coping with the job": Prison staff responding to self-harm in three English female prisons: A qualitative study. The Journal of Forensic Psychiatry \& Psychology, 28(6), 811-824. https://doi.org/10.1080/14789949.2017.1331369.

Walsh, B. (2007). Clinical assessment of self-injury: A practical guide. Journal of Clinical Psychology, 63(11), 1057-1068. https://doi.org/10.1002/jclp.20413.

Wilkinson, P., Kelvin, R., Roberts, C., Dubicka, B., \& Goodyer, I. (2011). Clinical and psychosocial predictors of suicide attempts and nonsuicidal self-injury in the Adolescent Depression Antidepressants and Psychotherapy Trial (ADAPT). American Journal of Psychiatry, 168(5), 495-501. https://doi.org/10.1176/appi.ajp.2010. 10050718.

Winchel, R. M., \& Stanley, M. (1991). Self-injurious behavior: A review of the behavior and biology of self-mutilation. The American Journal of Psychiatry, 148(3), 306-317. https://doi.org/10.1176/ajp.148.3.306.

Zahl, D. L., \& Hawton, K. (2004). Repetition of deliberate self-harm and subsequent suicide risk: Long-term follow-up study of 11583 patients. The British Journal of Psychiatry, 185(1), 70-75. https://doi.org/10.1192/bjp.185.1.70. 